Jurnal

Kardiologi Indonesia

J Kardiol Indones. 2014;35:134-6

ISSN 01 26/3773

\title{
Fibrilasi Atrial dengan Takikardia QRS Lebar
}

\author{
Yoga Yuniadi
}

S

eorang pria Bngladesh, 65 tahun datng ke UGD dengan keluhan mau pingsan. Pasien adalah pasien lama dengan $3 \mathrm{VD}$ yang sudah dilakukan revaskularisasi lengkap dengan pemasangan stent. Riwayat medis sebelumnya adalah rawat inap berulang karena ADHF. Hasil ekokardiografi menunjukkan suatu disfungsi ventrikel kiri berat, fraksi ejeksi (EF) 35\%, dimensi end diastolik ventrikel kiri (EDD) $66 \mathrm{~mm}$ dan dimensi atrium kiri (LAD) $52 \mathrm{~mm}$. Pemeriksaan fisik dalam batas normal. Rekaman EKG tampak seperti di bawah ini:

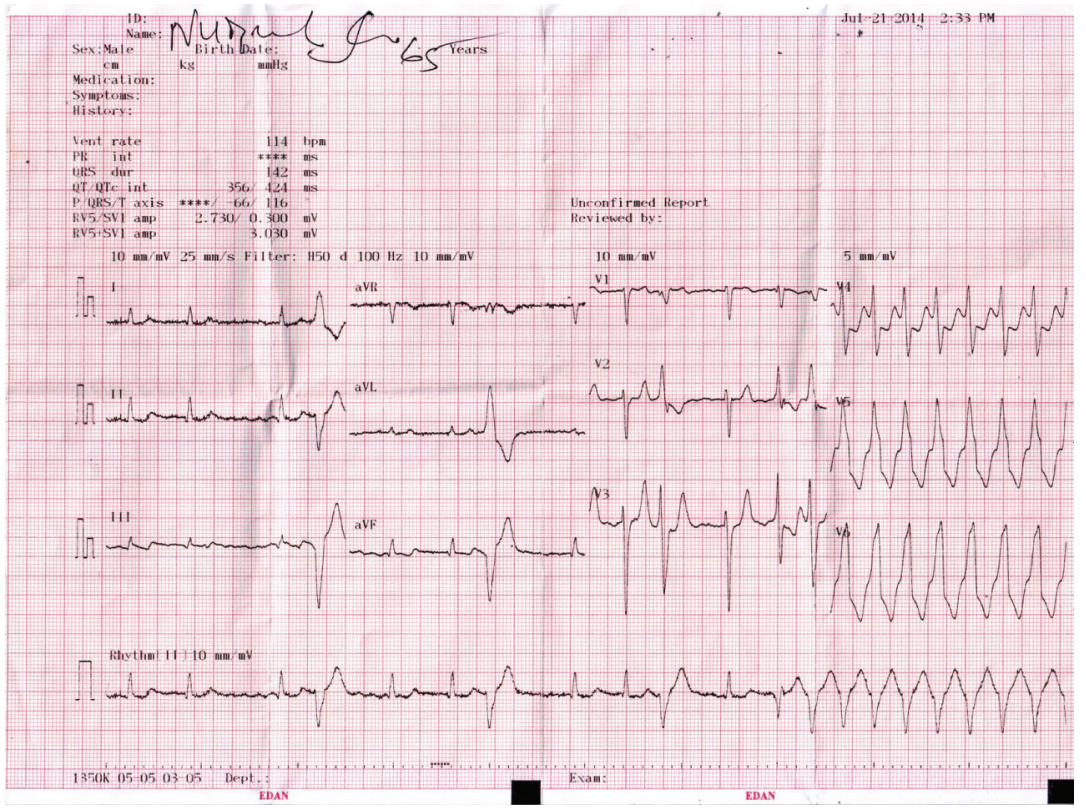

Gambar 1. Rekaman EKG 12-sadapan menunjukkan irama dasar yang iregular dengan QRS sempit yang diakhiri dengan takikardia QRS lebar yang regular. (atas budi baik Dr Mokaddas Husein, Bangladesh)

\section{Alamat Korespondensi}

Dr. dr. Yoga Yuniadi, SpJP. Divisi Aritmia, Departemen Kardiologi dan Kedokteran Vaskular, FKUI dan Pusat Jantung Nasional Harapan Kita, Jakarta. E-mail: yogay136@gmail.com
Apa diagnosis EKG pasien ini dan bagaimana tatalaksana selanjutnya?

Pasien adalah penderita gagal jantung kronik dengan 
penyakit dasar penyakit jantung koroner. Selama ini pasien berulang kali dirawat karena ADHF (Acute Decompensated Heart Failure). Pada perawatan kali ini terdapat keluhan baru yaitu hampir pingsan.

Rekaman EKG di atas adalah suatu irama fibrilasi atrial dengan VPC (Ventricle Premature Contraction) yang kemudian berubah menjadi suatu takikadia ventrikel. Perhatikan sadapan II panjang. Fibrilasi atrial cukup mudah dilihat pada bagian awal sadapan II panjang yaitu adanya gelombang fibrilasi dan QRS sempit yang iregular. Terlihat 3 buah VPC yang kemudian berdegenerasi menjadi takikardi ventrikel (TV) dengan morfologi yang sama dengan VPC.

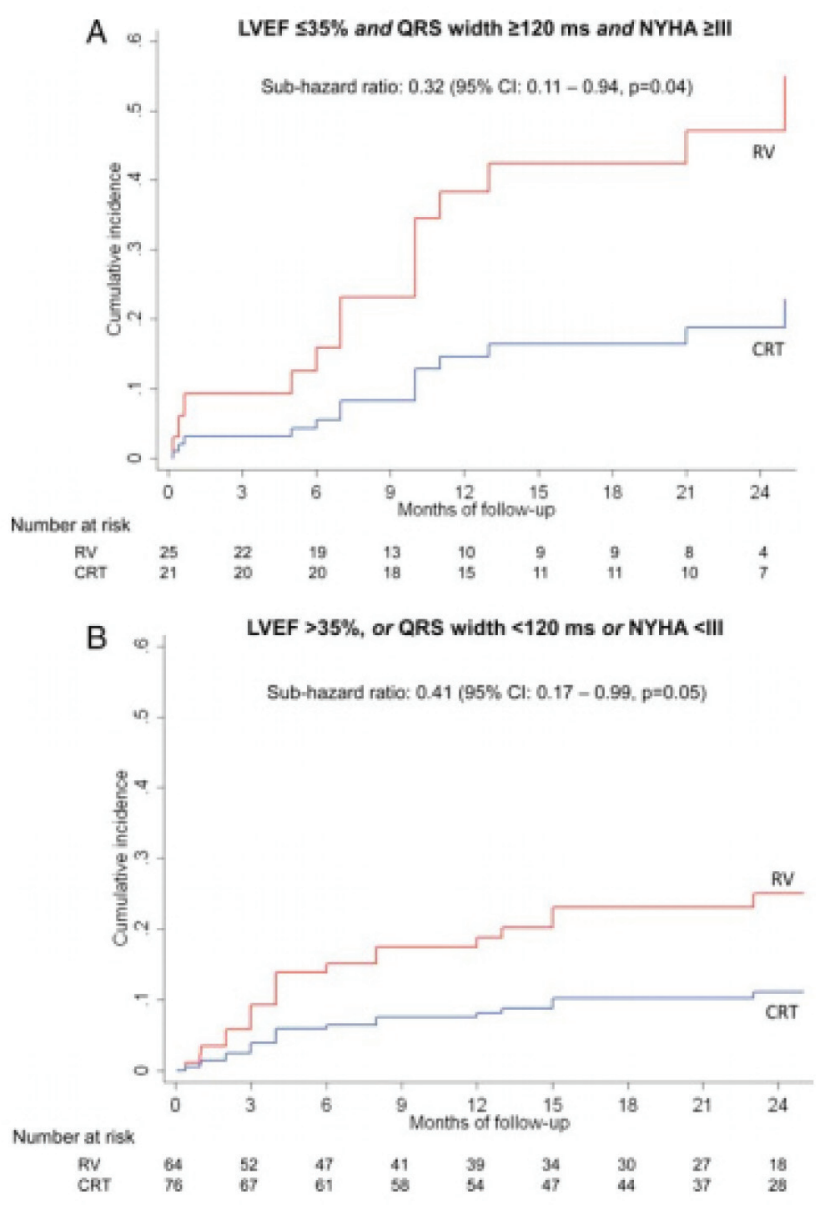

Gambar 2. Risiko primary composite endpoint (kematian akibat gagal jantung, rawat inap karena gagal jantung, atau perburukan gagal jantung) (A) Pasien yang memenuhi kriteria rekomendasi kebanyakan guidelines untuk implantasi CRT, (B) Pasien yang tidak memenuhi rekomendasi guidelines.
Pasien dengan disfungsi ventrikel kiri yang berat akan mudah mengalami ADHF bila respon ventrikel cepat terjadi pada saat AF atau ketika terjadi TV. TV juga dapat menyebabkan gejala mau pingsan bahkan dapat berakibat fatal.

Karena pasien sering mengalami rawat inap ADHF dengan pencetus fibrilasi atrial dengan respon ventrikel cepat maka dapat disimpulkan bahwa kendali laju dengan medikamentosa tidak memadai pada pasien ini. Kendali irama memakai medikamentosa pada kasu fibrilasi atrial yang kronis dengan ukuran LA yang besar juga tidak efektif. Begitu juga ablasi fibrilasi atrial dengan teknik isolasi vena pulmonalis dengan atau tanpa ablasi linear seringkali mengalami rekurensi fibrilasi atrial.

Oleh karena itu terapi yang dipilih untuk pasien dengan karakteristik: Fibrilasi atrial yang gagal kendali laju dan tidak cocok untuk kendali irama, disfungsi LV berat $(\mathrm{EF} \leq 35 \%)$, episode takikardia ventrikel yang berpotensi fatal; adalah melakukan ablasi $A V$ junction kemudian memasang CRTD. Dengan pendekatan ablate and pace ini maka fibrilasi atrial terkontrol, terdapat benefit resinkronisasi biventrikular dan prevensi kematian jantung mendadak.

Ablasi $A V$ junction dan pemacuan dilakukan pada pasien yang tidak respon terhadap obat-obatan atau bila obat menimbulkan efek samping (indikasi Kelas IIa). ${ }^{1}$ Ablate and pace terbukti secara signifikan memperbaiki kejadian gagal jantung, palpitasi, dyspnoe on effort, intoleransi terhadap latihan, dan fatig dibandingkan terapi medikamentosa., 3 Tetapi pemacuan ventrikel jangka panjang menimbulkan kekhawatiran terjadinya disfungsi ventrikel kiri di kemudian hari. Berlainan dengan pasien blok AV total, pada pasien FA kekhawatiran itu terbukti tidak benar. Lim $\mathrm{dkk}^{4}$ melakukan studi kohort jangka panjang untuk mengetahui pengaruh ablate and pace terhadap fungsi jantung dan kualitas hidup. Ternyata baik pada kelompok ablate and pace maupun kelompok medikamentosa sama-sama terjadi penurunan fungsi jantung dalam pengamatan 5 tahun. Walaupun penurunan ejeksi fraksi itu bermakna secara statistik akan tetapi secara klinis tidak penting karena nilai ejeksi fraksi pada tahun ke 5 tetap normal. Kualitas hidup yang dinilai dengan kuesioner CAST menunjukkan nilai yang lebih baik pada kelompok ablate and pace. ${ }^{4}$ Regularitas laju jantung dan eliminasi takikardia pasca ablate and pace diduga merupakan mekanisme perbaikan fungsi jantung melalui perbaikan takikardiomiopati dan perbaikan hemodinamik. ${ }^{5}$ 
Sebuah studi acak terkontrol secara elegan memperlihatkan bahwa implantasi cardiac resynchronization therapy (CRT) pasca ablasi $A V$ junction lebih baik daripada implantasi pacu jantung di ventrikel kanan. Manfaat ini didapatkan baik pada pasien dengan fraksi ejeksi dasar yang baik maupun disfungsi. Tetapi pada pasien dengan fraksi ejeksi dasar yang jelek $(\mathrm{EF} \leq 35 \%$ dan $\mathrm{QRS} \geq 120 \mathrm{mdet})$ manfaatnya lebih nyata (Gambar 2). ${ }^{6}$

Adapun alasan implantasi CRTD pada pasien ini adalah dokumentasi takikardia ventrikel yang simtomatik. Beberapa uji klinis mayor telah membuktikan keunggulan CRT plus defibrillator (CRTD) dibandingkan CRT pada kelompok pasien dengan disfungsi ventrikel kiri dan takikardia ventrikel.7, 8

\section{Daftar Pustaka}

1. Fuster V, Ryden LE, Cannom DS, Crijns HJ, Curtis AB, Ellenbogen KA, Halperin JL, Le Heuzey JY, Kay GN, Lowe JE, Olsson SB, Prystowsky EN, Tamargo JL, Wann S, Smith SC, Jr., Jacobs AK, Adams CD, Anderson JL, Antman EM, Hunt SA, Nishimura R, Ornato JP, Page RL, Riegel B, Priori SG, Blanc JJ, Budaj A, Camm AJ, Dean V, Deckers JW, Despres C, Dickstein K, Lekakis J, McGregor K, Metra M, Morais J, Osterspey A, Zamorano JL. ACC/AHA/ESC 2006 guidelines for the management of patients with atrial fibrillation: full text: a report of the American College of Cardiology/American Heart Association Task Force on practice guidelines and the European Society of Cardiology Committee for Practice Guidelines (Writing Committee to Revise the 2001 guidelines for the management of patients with atrial fibrillation) developed in collaboration with the European Heart Rhythm Association and the Heart Rhythm Society. Europace. 2006;8(9):651-745.

2. Brignole M, Gianfranchi L, Menozzi C, Alboni P, Musso G,
Bongiorni MG, Gasparini M, Raviele A, Lolli G, Paparella N, Acquarone S. Assessment of atrioventricular junction ablation and DDDR mode-switching pacemaker versus pharmacological treatment in patients with severely symptomatic paroxysmal atrial fibrillation: a randomized controlled study. Circulation. 1997;96(8):2617-2624.

3. Marshall HJ, Harris ZI, Griffith MJ, Holder RL, Gammage MD. Prospective randomized study of ablation and pacing versus medical therapy for paroxysmal atrial fibrillation: effects of pacing mode and mode-switch algorithm. Circulation. 1999;99(12):1587-1592.

4. Lim KT, Davis MJ, Powell A, Arnolda L, Moulden K, Bulsara $\mathrm{M}$, Weerasooriya R. Ablate and pace strategy for atrial fibrillation: long-term outcome of AIRCRAFT trial. Europace. 2007;9(7):498-505.

5. Ueng KC, Tsai TP, Tsai CF, Wu DJ, Lin CS, Lee SH, Chen SA. Acute and long-term effects of atrioventricular junction ablation and VVIR pacemaker in symptomatic patients with chronic lone atrial fibrillation and normal ventricular response. J Cardiovasc Electrophysiol. 2001;12(3):303-309.

6. Brignole M, Botto G, Mont L, Iacopino S, De Marchi G, Oddone D, Luzi M, Tolosana JM, Navazio A, Menozzi C. Cardiac resynchronization therapy in patients undergoing atrioventricular junction ablation for permanent atrial fibrillation: a randomized trial. Eur Heart J. 2011;32(19):2420-2429.

7. Moss AJ, Hall WJ, Cannom DS, Daubert JP, Higgins SL, Klein H, Levine JH, Saksena S, Waldo AL, Wilber D, Brown MW, Heo M. Improved survival with an implanted defibrillator in patients with coronary disease at high risk for ventricular arrhythmia. Multicenter Automatic Defibrillator Implantation Trial Investigators. N Engl J Med. 1996;335(26):1933-1940.

8. Moss AJ, Zareba W, Hall WJ, Klein H, Wilber DJ, Cannom DS, Daubert JP, Higgins SL, Brown MW, Andrews ML. Prophylactic implantation of a defibrillator in patients with myocardial infarction and reduced ejection fraction. $N$ Engl J Med. 2002;346(12):877-883. 